\section{Advertising, supplements and the role of the correspondence column}

\author{
International Committee of \\ M edical Journal E ditors
}

\section{ADVERTISING}

Most medical journals carry advertising, which generates income for their publishers, but advertising must not be allowed to influence editorial decisions. Editors must have full responsibility for advertising policy. Readers should be able to distinguish readily between advertising and editorial material. The juxtaposition of editorial and advertising material on the same products or subjects should be avoided, and advertising should not be sold on the condition that it will appear in the same issue as a particular article.

Journals should not be dominated by advertising, but editors should be careful about publishing advertisements from only one or two advertisers as readers may perceive that the editor has been influenced by these advertisers.

Journals should not carry advertisements for products that have proved to be seriously harmful to health-for example, tobacco. Editors should ensure that existing standards for advertisements are enforced or develop their own standards. Finally, editors should consider all criticisms of advertisements for publication.

\section{SUPPLEMENTS}

Supplements are collections of papers that deal with related issues or topics, are published as a separate issue of the journal or as a second part of a regular issue, and are usually funded by sources other than the journal's publisher. Supplements can serve useful purposes: education, exchange of research information, ease of access to focused content, and improved cooperation between academic and corporate entities. Because of the funding sources, the content of supplements can reflect biases in choice of topics and view- points. Editors should therefore consider the following principles.

1. The journal editor must take full responsibility for the policies, practices, and content of supplements. The journal editor must approve the appointment of any editor of the supplement and retain the authority to reject papers.

2. The sources of funding for the research, meeting, and publication should be clearly stated and prominently located in the supplement, preferably on each page. Whenever possible, funding should come from more than one sponsor.

3. Advertising in supplements should follow the same policies as those of the rest of the journal.

4. Editors should enable readers to distinguish readily between ordinary editorial pages and supplement pages.

5. Editing by the funding organization should not be permitted.

6. Journal editors and supplement editors should not accept personal favors or excessive compensation from sponsors of supplements.

7. Secondary publication in supplements should be clearly identified by the citation of the original paper. Redundant publication should be avoided.

\section{THE ROLE OF THE CORRESPONDENCE COLUMN}

All biomedical journals should have a section carrying comments, questions, or criticisms about articles they have published and where the original authors can respond. Usually, but not necessarily, this may take the form of a correspondence column. The lack of such a section denies readers the possibility of responding to articles in the same journal that published the original work.

\footnotetext{
Inquiries and comments: should be sent to the São Paulo Medical Journal (Revista Paulista de Medicina) secretariat office, Associação Paulista de Medicina, Av. Brigadeiro Luiz Antonio, 278, 7th floor. 01318-901 - E-mail revistas@apm.org.br

The notes in this serie are excerpts from: International Committee of Medical Journal Editors. Uniform Requirements for Manuscripts Submitted to Biomedical Journals. Ann Intern Med 1997 Jan 1;126(1):3647. Available on website: http://www.acponline.org/journals/annals/ 01jan97/unifreqr.htm This article includes: issues to consider before submitting a manuscript, requirements for submission of manuscripts, sending the manuscript to the journal, and a separate statements.
} 


\section{Competing Manuscripts Based on the Same Study} International Committee of
M edical Journal E ditors

Editors may receive manuscripts from different authors offering competing interpretations of the same study. They have to decide whether to review competing manuscripts submitted to them more or less simultaneously by different groups or authors, or they may be asked to consider one such manuscript while a competing manuscript has been or will be submitted to another journal. Setting aside the unresolved question of ownership of data, we discuss here what editors ought to do when confronted with the submission of competing manuscripts based on the same study.

Two kinds of multiple submissions are considered: submissions by coworkers who disagree on the analysis and interpretation of their study, and submissions by coworkers who disagree on what the facts are and which data should be reported.

The following general observations may help editors and others dealing with this problem.

\section{Differences in Analysis or Interpretation}

Journals would not normally wish to publish separate articles by contending members of a research team who have differing analyses and interpretations of the data, and submission of such manuscripts should be discouraged. If coworkers cannot resolve their differences in interpretation before submitting a manuscript, they should consider submitting one manuscript containing multiple interpretations and calling their dispute to the attention of the editor so that reviewers can focus on the problem. One of the important functions of peer review is to evaluate the authors' analysis and interpretation and to suggest appropriate changes to the conclusions before publication. Alternatively, after the disputed version is published, editors may wish to consider a letter to the editor or a second manuscript from the dissenting authors. Multiple submissions present editors with a dilemma. Publication of contending manuscripts to air authors' disputes may waste journal space and confuse readers. On the other hand, if editors knowingly publish a manuscript written by only some of the collaborating team, they could be denying the rest of the team their legitimate coauthorship rights.

\section{Differences in Reported M ethods or Results}

Workers sometimes differ in their opinions about what was actually done or observed and which data ought to be reported. Peer review cannot be expected to resolve this problem. Editors should decline further consideration of such multiple submissions until the problem is settled. Furthermore, if there are allegations of dishonesty or fraud, editors should inform the appropriate authorities.

The cases described above should be distinguished from instances in which independent, noncollaborating authors submit separate manuscripts based on different analyses of data that are publicly available. In this circumstance, editorial consideration of multiple submissions may be justified, and there may even be a good reason for publishing more than one manuscript because different analytical approaches may be complementary and equally valid.

Inquiries and comments: should be sent to the São Paulo Medical Journal (Revista Paulista de Medicina) secretariat office, Associação Paulista de Medicina, Av. Brigadeiro Luiz Antonio, 278, 7th floor. 01318-901 - E-mail: revistas@apm.org.br

The notes in this serie are excerpts from: International Committee of Medical Journal Editors. Uniform Requirements for Manuscripts Submitted to Biomedical Journals. Ann Intern Med 1997 Jan 1;126(1):3647. Available on website: http://www.acponline.org/journals/annals/ 01jan97/unifreqr.htm This article includes: issues to consider before submitting a manuscript, requirements for submission of manuscripts, sending the manuscript to the journal, and a separate statements. 